(7)

28

30

\title{
Congener patterns of persistent organic pollutants establish the extent of contaminant biotransport by Pacific salmon in the Great Lakes
}

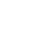

5

(1)

8

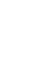

(1)

11

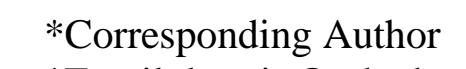

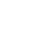

8

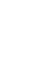

0

1

2

3

4

5

26

7

9

1



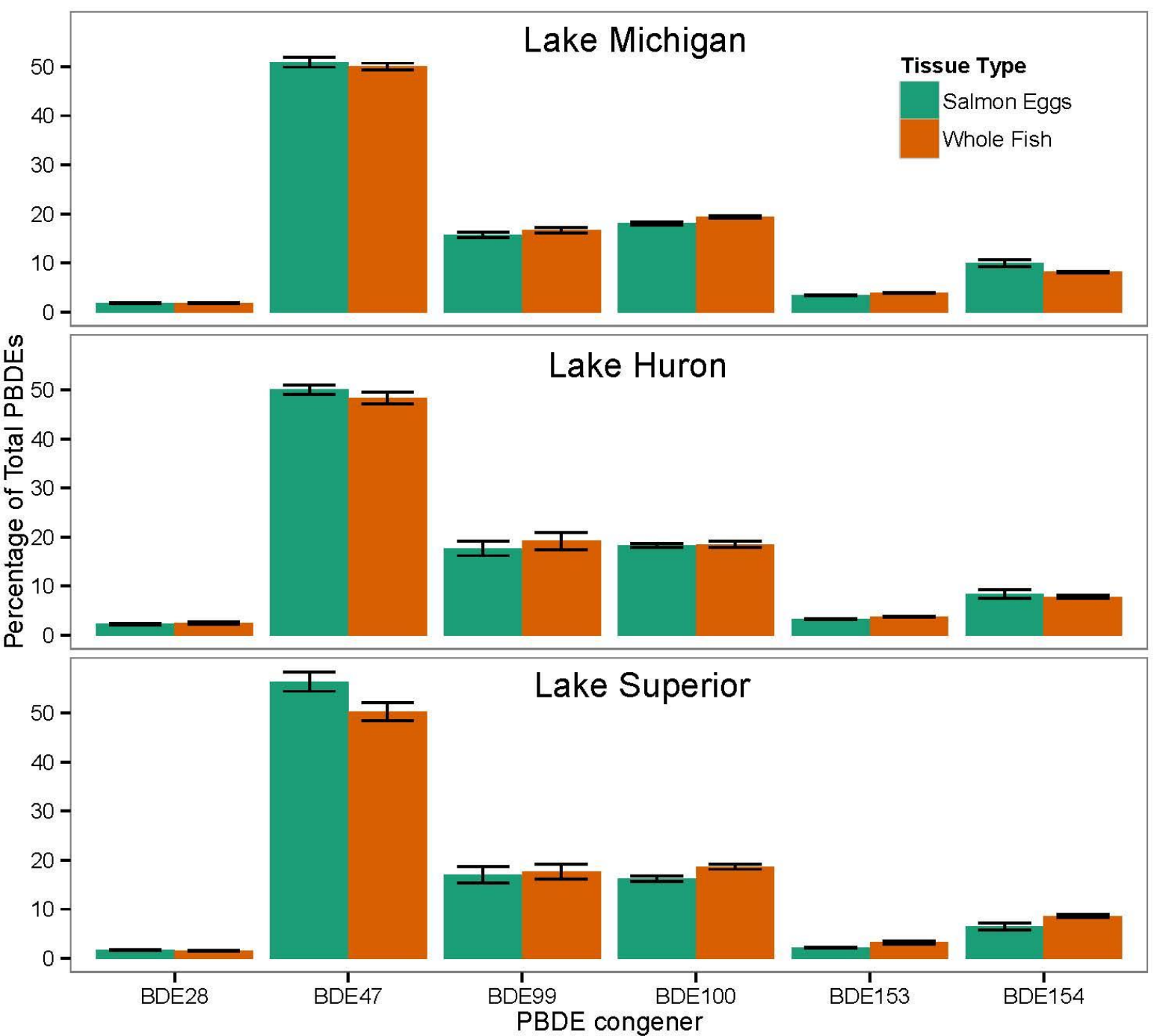

34 Figure S1. PBDE congener pattern (mean percentage \pm standard error) of salmon eggs and whole 35 fish from lakes Michigan (eggs $\mathrm{N}=16$, tissue $\mathrm{N}=28$ ), Huron (eggs $\mathrm{N}=4$, tissue $\mathrm{N}=9$ ), and Superior 36 (eggs $\mathrm{N}=7$, tissue $\mathrm{N}=12$ ). PBDE congeners quantified were BDE28, BDE47, BDE99, BDE100, 37 BDE153, and BDE154. 

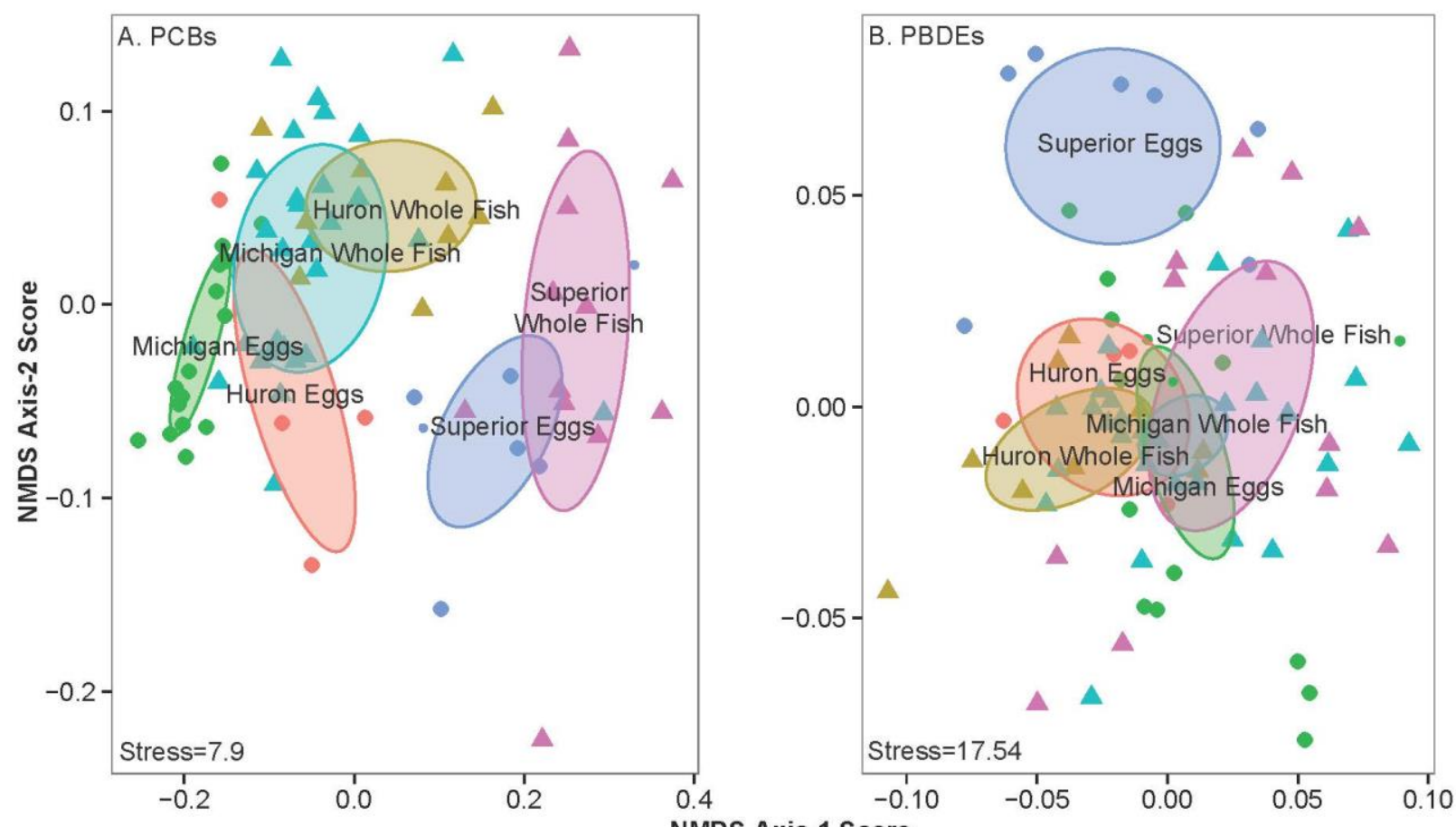

39

NMDS Axis-1 Score

40 Figure S2. Non-metric, multidimensional scaling (NMDS) plots with 95\% confidence ellipses of

41 the mean for PCBs (A.) and PBDEs (B.) in salmon whole fish and eggs from lakes Michigan,

42 Huron, and Superior. A convergent solution for PCBs was found after two iterations (stress=7.9)

43 and for PBDEs after three iterations (stress=17.54). Tissue samples are represented by triangles

44 and egg samples by circles. Ellipses are the same color as corresponding data points.

45

46

47

48

49

50

51

52

53

54

55

56

57 
58 Table S1. Pairwise Bonferroni comparisons for PCB and PBDE PERMANOVA models in

59 salmon from lakes Michigan, Huron, and Superior. The alpha value for each pairwise

60 comparison was 0.006 (0.05/9 comparisons per POP class). Significant comparisons are in bold.

61 For each contaminant we compared differences in tissue and pattern among basins. In addition,

62 we also compared tissue and egg patterns within a given basin.

\begin{tabular}{|c|c|c|c|c|}
\hline POP & Source & Comparison & $\mathrm{F}$ & p-value \\
\hline \multirow[t]{9}{*}{ PCB } & \multirow[t]{3}{*}{ Tissue } & Michigan-Huron & 4.37 & 0.006 \\
\hline & & Michigan-Superior & 42.72 & 0.001 \\
\hline & & Superior-Huron & 24.20 & 0.001 \\
\hline & \multirow[t]{3}{*}{ Eggs } & Michigan-Huron & 3.46 & 0.020 \\
\hline & & Michigan-Superior & 79.62 & 0.001 \\
\hline & & Superior-Huron & 18.17 & 0.003 \\
\hline & \multirow[t]{3}{*}{ Tissue-Eggs } & Michigan & 15.35 & 0.001 \\
\hline & & Huron & 6.88 & 0.001 \\
\hline & & Superior & 3.10 & 0.010 \\
\hline \multirow[t]{9}{*}{ PBDE } & \multirow[t]{3}{*}{ Tissue } & Michigan-Huron & 2.71 & 0.060 \\
\hline & & Michigan-Superior & 0.83 & 0.420 \\
\hline & & Superior-Huron & 1.24 & 0.266 \\
\hline & \multirow[t]{3}{*}{ Eggs } & Michigan-Huron & 0.76 & 0.460 \\
\hline & & Michigan-Superior & 6.74 & 0.004 \\
\hline & & Superior-Huron & 3.73 & 0.040 \\
\hline & \multirow[t]{3}{*}{ Tissue-Eggs } & Michigan & 3.10 & 0.040 \\
\hline & & Huron & 0.54 & 0.590 \\
\hline & & Superior & 4.20 & 0.020 \\
\hline
\end{tabular}

64

65

66

67

68

69

70

71

72

73

74

75 
Table S2. Pairwise Bonferroni comparisons for PCB models in PERMANOVA brook trout and

77 mottled sculpin in reaches with salmon present and salmon absent from lakes Michigan, Huron,

78 and Superior. The alpha value for each pairwise comparison was 0.00625 (0.05/8 comparisons

79 per basin). Significant comparisons are in bold.

$\begin{array}{lllll}\text { POP } & \text { Basin } & \text { Comparison } & \text { F } & \text { p-value } \\ \text { PCB } & \text { Michigan } & \text { Brook Trout-Salmon Present: Brook Trout-Salmon Absent } & 5.61 & \mathbf{0 . 0 0 1} \\ & & \text { Brook Trout-Salmon Present: Salmon Spawners } & 1.86 & 0.020 \\ & & 18.35 & \mathbf{0 . 0 0 1} \\ & \text { Brook Trout-Salmon Absent:Salmon Spawners } & 4.96 & \mathbf{0 . 0 0 1} \\ & \text { Mottled Sculpin-Salmon Present: Mottled Sculpin-Salmon Absent } & 50.17 & \mathbf{0 . 0 0 1} \\ & \text { Mottled Sculpin-Salmon Present: Salmon Spawners } & 39.15 & \mathbf{0 . 0 0 1} \\ & \text { Mottled Sculpin-Salmon Absent:Salmon Spawners } & 13.20 & \mathbf{0 . 0 0 1} \\ & \text { Brook Trout-Salmon Present: Mottled Sculpin-Salmon Present } & 8.95 & \mathbf{0 . 0 0 1} \\ & \text { Brook Trout-Salmon Absent: Mottled Sculpin-Salmon Absent } & 3.40 & 0.003 \\ & \text { Brook Trout-Salmon Present: Brook Trout-Salmon Absent } & 2.23 & 0.039 \\ & \text { Brook Trout-Salmon Present: Salmon Spawners } & 8.90 & \mathbf{0 . 0 0 1} \\ & \text { Brook Trout-Salmon Absent:Salmon Spawners } & 12.17 & \mathbf{0 . 0 0 1} \\ & \text { Mottled Sculpin-Salmon Present: Mottled Sculpin-Salmon Absent } & \text { NA } & \text { NA } \\ & \text { Mottled Sculpin-Salmon Present: Salmon Spawners } & \text { NA } & \text { NA } \\ & \text { Mottled Sculpin-Salmon Absent:Salmon Spawners } & 4.50 & 0.004 \\ & \text { Brook Trout-Salmon Present: Mottled Sculpin-Salmon Present } & \text { NA } & \text { NA } \\ & \text { Brook Trout-Salmon Absent: Mottled Sculpin-Salmon Absent } & 14.52 & \mathbf{0 . 0 0 1} \\ & \text { Brook Trout-Salmon Present: Brook Trout-Salmon Absent } & 6.66 & \mathbf{0 . 0 0 1} \\ & \text { Brook Trout-Salmon Present: Salmon Spawners } & 0.922 & 0.5 \\ & \text { Brook Trout-Salmon Absent:Salmon Spawners } & 23.70 & \mathbf{0 . 0 0 1} \\ & \text { Mottled Sculpin-Salmon Present: Mottled Sculpin-Salmon Absent } & 1.14 & 0.335 \\ & \text { Mottled Sculpin-Salmon Present: Salmon Spawners } & 33.38 & \mathbf{0 . 0 0 1} \\ & \text { Mottled Sculpin-Salmon Absent:Salmon Spawners } & 3.50 & \mathbf{0 . 0 0 8} \\ & \text { Brook Trout-Salmon Present: Mottled Sculpin-Salmon Present } & 2.14 & \mathbf{0 . 0 8 0}\end{array}$


92 Table S3. Pairwise Bonferroni comparisons for PBDE PERMANOVA models for brook trout 93 and mottled sculpin in reaches with salmon present and salmon absent from lakes Michigan, 94 Huron, and Superior. The alpha value for each pairwise comparison was $0.00625(0.05 / 8$

95 comparisons per basin). Significant comparisons are italicized.

\begin{tabular}{|c|c|c|c|c|}
\hline POP & Basin & Comparison & $\mathrm{F}$ & p-value \\
\hline \multirow[t]{24}{*}{ PBDE } & \multirow[t]{8}{*}{ Michigan } & Brook Trout-Salmon Present: Brook Trout-Salmon Absent & 4.95 & 0.009 \\
\hline & & Brook Trout-Salmon Present: Salmon Spawners & 1.68 & 0.170 \\
\hline & & Brook Trout-Salmon Absent:Salmon Spawners & 20.53 & 0.001 \\
\hline & & Mottled Sculpin-Salmon Present: Mottled Sculpin-Salmon Absent & 4.72 & 0.001 \\
\hline & & Mottled Sculpin-Salmon Present: Salmon Spawners & 92.52 & 0.001 \\
\hline & & Mottled Sculpin-Salmon Absent:Salmon Spawners & 10.69 & 0.001 \\
\hline & & Brook Trout-Salmon Present: Mottled Sculpin-Salmon Present & 23.21 & 0.001 \\
\hline & & Brook Trout-Salmon Absent: Mottled Sculpin-Salmon Absent & 2.92 & 0.040 \\
\hline & \multirow[t]{8}{*}{ Huron } & Brook Trout-Salmon Present: Brook Trout-Salmon Absent & 4.22 & 0.003 \\
\hline & & Brook Trout-Salmon Present: Salmon Spawners & 1.89 & 0.169 \\
\hline & & Brook Trout-Salmon Absent:Salmon Spawners & 13.07 & 0.001 \\
\hline & & Mottled Sculpin-Salmon Present: Mottled Sculpin-Salmon Absent & NA & NA \\
\hline & & Mottled Sculpin-Salmon Present: Salmon Spawners & 12.35 & 0.001 \\
\hline & & Mottled Sculpin-Salmon Absent:Salmon Spawners & NA & NA \\
\hline & & Brook Trout-Salmon Present: Mottled Sculpin-Salmon Present & 3.28 & 0.032 \\
\hline & & Brook Trout-Salmon Absent: Mottled Sculpin-Salmon Absent & NA & NA \\
\hline & \multirow[t]{8}{*}{ Superior } & Brook Trout-Salmon Present: Brook Trout-Salmon Absent & 0.81 & 0.470 \\
\hline & & Brook Trout-Salmon Present: Salmon Spawners & 2.19 & 0.130 \\
\hline & & Brook Trout-Salmon Absent:Salmon Spawners & 16.81 & 0.001 \\
\hline & & Mottled Sculpin-Salmon Present: Mottled Sculpin-Salmon Absent & 1.18 & 0.350 \\
\hline & & Mottled Sculpin-Salmon Present: Salmon Spawners & 25.65 & 0.001 \\
\hline & & Mottled Sculpin-Salmon Absent:Salmon Spawners & 10.45 & 0.001 \\
\hline & & Brook Trout-Salmon Present: Mottled Sculpin-Salmon Present & 2.93 & 0.095 \\
\hline & & Brook Trout-Salmon Absent: Mottled Sculpin-Salmon Absent & 1.34 & 0.282 \\
\hline
\end{tabular}

